\title{
A Pruritic Linear Eruption After an Arthropod Bite
}

\section{Erupção Linear Pruriginosa Após Picada de Artrópode}

Ana Sofia PEREIRA $\triangle^{1}$, Rebeca CALADO², José Carlos CARDOSO ${ }^{2}$

Acta Med Port 2023 Apr;36(4):283-284 - https://doi.org/10.20344/amp.16988

Keywords: Insect Bites and Stings; Lymphangitis

Palavras-chave: Linfangite; Mordeduras e Picadas de Insetos

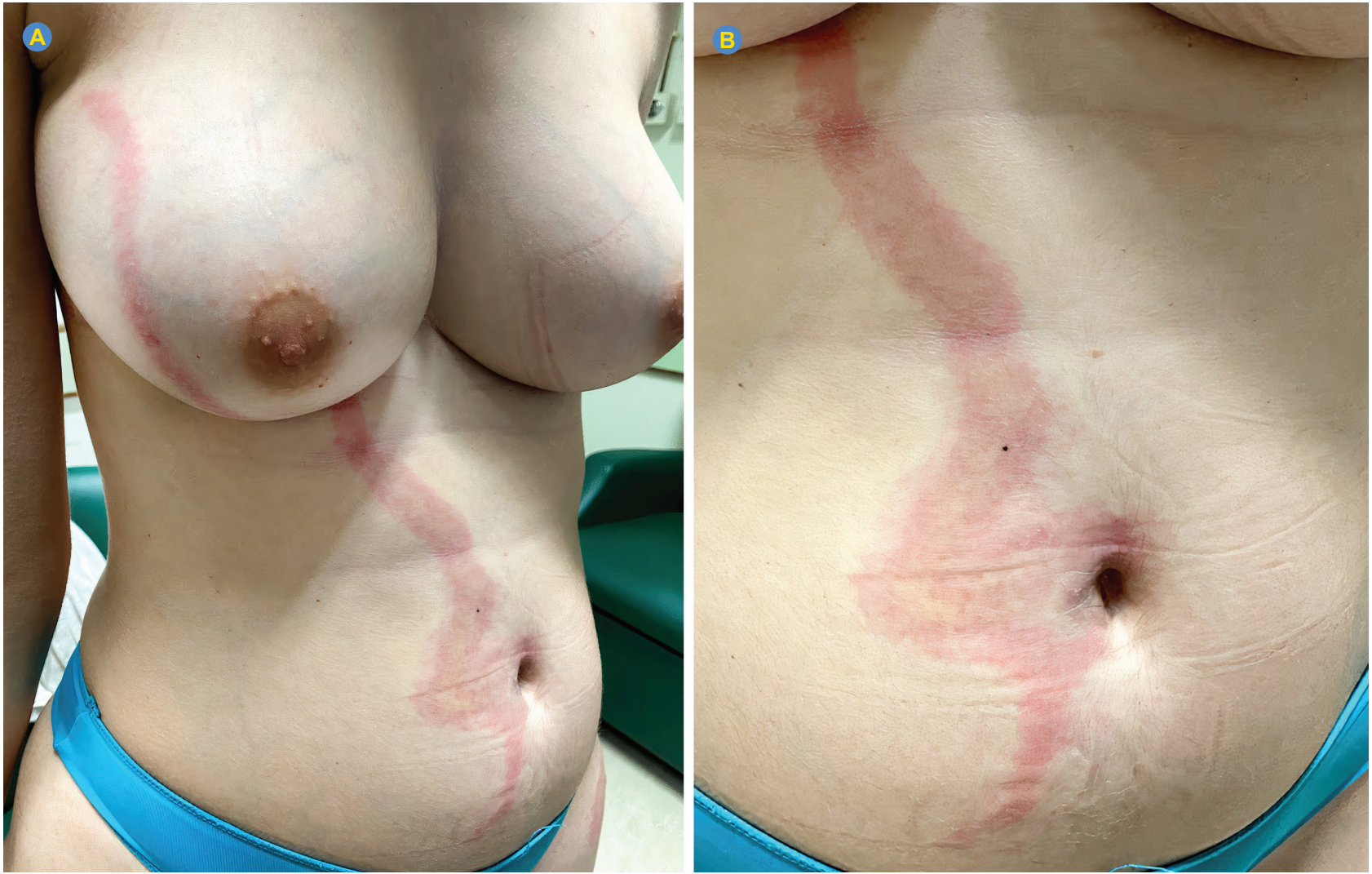

Figure 1 - (A) Linear erythematous streak from the lower abdomen to the right axilla; (B) A close-up of the area of the insect bite

A 25-year-old woman presented with a pruritic linear eruption on the anterior wall of the trunk that appeared 24 hours after a mosquito bite on the lower abdomen. On examination, one red streak starting from the area of the bite towards the right axillary fold was observed (Fig. 1). She denied any systemic symptoms and there were no palpable lymph nodes. Her medical history was unremarkable.

The anamnesis and the distinctive configuration of the lesion supported the diagnosis of insect bite-induced superficial lymphangitis. The patient was successfully treated with a one week course of oral antihistamines.

Superficial lymphangitis after an insect bite is an underrecognized entity, ${ }^{1}$ in which acute lymphangitis presents without fever and lymphadenopathy. ${ }^{1,2}$ To date, there are only a few cases reported. ${ }^{1-5}$ The pathogenesis presupposes a toxic or hypersensitivity reaction to insect toxins, ${ }^{3}$ which enter the lymphatic draining vessels and result in a linearly disposed inflammatory reaction of the overlying skin. 


\section{AUTHOR CONTRIBUTIONS}

ASP: Literature research, draft of the paper.

RC: Data acquisition and interpretation.

JCC: Critical review of the manuscript.

\section{PROTECTION OF HUMANS AND ANIMALS}

The authors declare that the procedures were followed according to the regulations established by the Clinical Research and Ethics Committee and to the Helsinki Declaration of the World Medical Association updated in 2013.

\section{DATA CONFIDENTIALITY}

The authors declare having followed the protocols in

\section{REFERENCES}

1. Ferdman R. Superficial allergic lymphangitis with a cutaneous recall reaction to a mosquito bite. Ann Allergy Asthma Immunol. 2019;123:521 2.

2. Piccolo V, Russo T, Picciocchi R. Superficial lymphangitis after insect bite. J Pediatr. 2013;163:299.

3. Marque M, Girard C, Guillot B. Superficial lymphangitis after use at their working center regarding patients' data publication.

\section{INFORMED CONSENT}

Obtained.

\section{COMPETING INTERESTS}

All authors report no competing interests.

\section{FUNDING SOURCES}

The authors declare that there were no external sources of study for the performance of this article.

arthropod bite: a distinctive but underrecognized entity? Dermatology. 2008;217:262-7.

4. Meyer Sauteur PM, Orban P, Theiler M. Recurrent superficial lymphangitis after insect bites. Arch Dis Child. 2018:103:296.

5. Smith LR, Honig PJ. Lymphangitis of the anterior chest Wall. Cutis. 1980;26:412-3. 